\title{
Trends in reports of child maltreatment in the Northern Territory, 1999-2010
}

\section{Steven L Guthridge MB BS, MTH, FAFPHM Director, ' and Postgraduate Student ${ }^{2}$ \\ Philip Ryan MB BS, FAFPHM Professor of Health Research \\ John R Condon PhD, FAFPHM Principal Research Fellow}

Leah M Bromfield BAppSci(Psych)(Hons),

Associate Professo and Deputy Director

John R Moss MSocSci, MB BS, FPHAA Associate Professor

John W Lynch $\mathrm{PhD}, \mathrm{MPH}$

Professor of Public Health

1 Health Gains Planning Northern Territory Department of Health Darwin, NT. 2 School of Population Health University of Adelaide Adelaide, SA.

3 Menzies School of Health Research

Charles Darwin University, Darwin, NT.

4 Australian Centre for Child Protection, University of South Australia,

Adelaide, SA.

steven.guthridge@ adelaide.edu.au

MJA 2012; 197: 637-641 doi: 10.5694/mjal2.10133

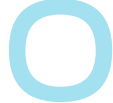
ver the past decade, coroners' reports and government inquiries have highlighted the extent and tragedy of child maltreatment within Australia. ${ }^{1-3}$ The high risk among Aboriginal children has attracted particular attention. ${ }^{4-6}$ An increase in notifications of suspected maltreatment has been both a driver and an outcome of public attention, and by the 2009-10 financial year there were 286437 notifications involving ${ }^{7} 187314$ Australian children. The increase has not been consistent in all jurisdictions, with the Northern Territory showing a threefold increase over 5 years, to 6585 notifications in 2009-10. ${ }^{7}$

Central to increased community concern for NT children has been the protection of Aboriginal children from sexual abuse. In 2007, the NT report Little children are sacred stated "sexual abuse of Aboriginal children is common, widespread and grossly underreported". ${ }^{8}$ The federal government's "emergency response" to the release of the report was immediate and controversial, ${ }^{9-11}$ but the initial emphasis on the identification of sexual abuse was moderated by the recognition that child sexual abuse could neither be identified by a screening test, nor be isolated from the wider risks to children from poverty, unemployment, poor education, poor health, inadequate housing and alcohol misuse. In collaboration with the NT Government, the ongoing response includes programs for housing, income management and improved school participation, and a major expansion in primary health care services. $^{12}$

After the release of Little children are sacred, the media continued to expose frailties in NT child protection services, which were struggling to cope with the rapid increase in notifications of suspected maltreatment. In 2009, a second inquiry was established, this time to review child protection services. The findings were released in the Growing them strong, together report, which highlighted a

\section{Abstract \\ Objective: To examine trends in reports of child maltreatment to the Northern Territory Department of Children and Families among Aboriginal and non-} Aboriginal children.

Design, setting and subjects: A historical cohort study using administrative data collections of notifications and substantiated cases of maltreatment among children aged from 0 to 17 years.

Main outcome measures: Annual rates of notification and substantiation of different types of child maltreatment.

Results: From 1999 to 2010, the overall annual rates of notification for maltreatment of Aboriginal children showed an average increase of $21 \%$ (incidence rate ratio [IRR], 1.21; 95\% Cl, 1.19-1.24). The greatest increases were in notifications for neglect and emotional abuse. There were parallel increases in rates of substantiated cases of maltreatment. Among non-Aboriginal children, the overall annual rates of notification also increased (IRR, 1.10; 95\% Cl, 1.07-1.14); however, changes in annual rates of substantiated cases for all types of maltreatment were not statistically significant.

Conclusion: There have been considerable increases in both notifications and substantiated cases of child maltreatment, most prominently among Aboriginal children. It is possible that the observed increases reflect increasing incidence of maltreatment; however, they are also consistent with a mix of increased surveillance, improved service access, changes in policy and a shift in public attitudes. service overwhelmed by demand, understaffed, underresourced and demoralised by both actions and inaction. ${ }^{13}$ The shortcomings of responses by government services to Aboriginal child maltreatment have not been confined to the NT, and inquiries, including those in Western Australia, South Australia and New South Wales, have all drawn attention to the inadequacies of agency responses. ${ }^{4-6}$

We used NT Government child protection information to examine trends and characteristics of child maltreatment notifications and substantiated cases between 1999 and 2010, in the context of extensive reform and expansion of services.

\section{Methods}

Administrative information on child protection has been collected in the NT since 1982. The information is used for managing services and is also the source of selected data items that are published annually in national reports. ${ }^{7}$ A new data record is initiated
1 Definitions, legislation and reporting practices related to child protection in Australia

- Child maltreatment refers to non-accidental behaviour towards a child, outside the norms of conduct, that entails a risk of physical or emotional harm. Behaviour may be intentional or unintentional and includes acts of omission (neglect) or commission (abuse). Child maltreatment is commonly separated into four types: neglect, physical abuse, sexual abuse (including sexual exploitation) and emotional abuse. Neglect refers to failure to provide for a child's basic needs including food, shelter, medical treatment and supervision. Emotional abuse includes witnessing family violence. ${ }^{14}$

- There is some variation between Australian jurisdictions in child protection legislation and related reporting practices. ${ }^{14,15}$ Northern Territory legislation recognises that a child is in need of care and protection if the child has suffered or is likely to suffer harm or exploitation. In the NT, all adults are mandated to report any child that they suspect, on reasonable grounds, has been or is likely to be maltreated. These reports are recorded by the NT child protection agency as "notifications" and then reviewed. If the notification is consistent with maltreatment, it is referred for investigation. One possible outcome of an investigation is the substantiation that there is reasonable cause to believe that a child has been or is likely to be harmed. ${ }^{15}$ 
2 Number and rate of notifications, investigations and substantiated cases of child maltreatment,* by Aboriginality and time period (1999-2002, 2003-2006 and 2007-2010), Northern Territory

\begin{tabular}{|c|c|c|c|c|c|}
\hline & \multicolumn{2}{|c|}{ Notifications $(n=35112)^{\dagger}$} & \multirow{2}{*}{$\begin{array}{l}\text { Investigations } \\
\text { Number }\left(\%{ }^{\S}\right)\end{array}$} & \multicolumn{2}{|c|}{ Substantiated cases } \\
\hline & Number & Rate $^{\ddagger}(95 \% \mathrm{Cl})$ & & Number (\%") & Rate $^{\ddagger}(95 \% \mathrm{Cl})$ \\
\hline Aboriginal children & $n=23146$ & & $n=14054$ & $n=6447$ & \\
\hline 1999-2002 & 2918 & $29.4(28.4-30.5)$ & 1778 (60.9\%) & $926(52.1 \%)$ & $9.3(8.7-9.6)$ \\
\hline 2003-2006 & 5689 & $54.8(53.3-56.2)$ & 3692 (64.9\%) & $1814(49.1 \%)$ & 17.5 (16.7-18.3) \\
\hline 2007-2010 & 14539 & $134.2(132.0-136.4)$ & $8584(59.0 \%)$ & 3707 (43.2\%) & $34.2(33.1-35.3)$ \\
\hline Non-Aboriginal children & $n=11966$ & & $n=5619$ & $n=1962$ & \\
\hline 1999-2002 & 2802 & $20.0(19.3-20.8)$ & 1380 (49.3\%) & $564(40.9 \%)$ & $4.0(3.7-4.4)$ \\
\hline $2003-2006$ & 3236 & $23.6(22.8-24.4)$ & 1595 (49.3\%) & $623(39.1 \%)$ & $4.5(4.2-4.9)$ \\
\hline 2007-2010 & 5928 & $41.9(40.8-43.0)$ & $2644(44.6 \%)$ & 775 (29.3\%) & $5.4(5.1-5.9)$ \\
\hline
\end{tabular}

by a notification to the NT Department of Children and Families of an incident of suspected maltreatment. Each record includes demographic and incident details, and information on any subsequent investigation and substantiation. The type of maltreatment is recorded separately for notifications and any subsequent substantiation as one or more of four standard categories: emotional abuse, physical abuse, sexual abuse and neglect (Box 1). Several types of maltreatment may be recorded for a single notification and any subsequent substantiation. The type of maltreatment considered to be the most immediate risk is recorded as the primary type. If the same incident is reported from more than one source it is recorded as a single notification. Over time, a child may have multiple notifications and substantiations from different incidents.

We estimated population-based rates for notifications and substantiated cases, by Indigenous status, for three 4year time periods: 1999-2002, 20032006 and 2007-2010. We also calculated the proportions of notifications referred for investigation and the proportion of investigations that were substantiated. Annual rates of notifications and substantiated cases for each type of maltreatment and all types combined, by Indigenous status, were also calculated. We used Poisson regression to estimate the average annual increase in rate, expressed as incidence rate ratio (IRR). The number of children in notifications and in substantiations in each calendar year was calculated, along with the time trend for the ratio of notifications or substantiations per child.
The sources of notifications were aggregated to seven reporter groups. The relative contribution of each group was calculated for the 4-year time periods, by Indigenous status.

Population tables based on 2006 Australian Bureau of Statistics census estimates $^{16}$ were provided by the Health Gains Planning branch of the NT Department of Health. The study protocol was approved by the Human Research Ethics Committee of the NT Department of Health and Menzies School of Health Research (HREC 111501) and the Human Research Ethics Committee of the University of Adelaide (H-028-2011).

\section{Results}

\section{Number of notifications and substantiated cases}

During the study period, there were 35750 notifications for children aged from 0 to 17 years. Of these, 635 reports (1.8\%) were excluded from further analysis because of missing information on Indigenous status or sex. Of 35115 eligible notifications, 23147 (66\%) related to 10782 Aboriginal children and the remaining 11968 notifications (34\%) to 6322 non-Aboriginal children. Mean age at the time of the first notification was 5.8 years (95\% CI, 5.7-5.8 years) among Aboriginal children and 7.4 years (95\% CI, 7.3-7.6 years) among non-Aboriginal children. The notification rate was higher for girls than boys among both Aboriginal and non-Aboriginal children. Girls comprised $48 \%$ of notifications in the 0 12 -years age group among both
Aboriginal (9390/19520) and nonAboriginal children (4549/9480), but in the 13-17-years age group most notifications for both Aboriginal and non-Aboriginal children were among girls (66\% [2404/3627] and 62\% [1533/2488], respectively).

Among Aboriginal children, there was a substantial increase in the numbers of notifications and substantiations across all three time periods (Box 2). For all maltreatment types combined, the notification rate in 2007-2010 was 4.6 times the rate in 1999-2002, and the substantiation rate increased to 3.7 times the rate in 1999-2002. The proportion of notifications referred for investigation remained broadly stable, while the proportion of investigations that were subsequently substantiated declined from $52.1 \%$ to $43.2 \%$. Among nonAboriginal children, the notification and substantiation rates increased between the first and third time periods, but to a lesser extent than for Aboriginal children, to 2.1 times and 1.4 times, respectively. The proportion of notifications referred for investigation decreased from $49.3 \%$ in the first two time periods to $44.6 \%$. The proportion of investigations that were substantiated declined markedly across the time periods (from $40.9 \%$ to $29.3 \%$ ) (Box 2).

Changes in annual rates of notification and substantiation, by Aboriginality, are shown in Box 3. Among Aboriginal children, the rate of notification of children at risk of maltreatment increased from 29.7 notifications per 1000 children in 1999 to 155.5 per 1000 in 2010, an average increase of $21 \%$ per year. The rate for 
substantiated cases increased from 9.6 per 1000 to 47.3 per 1000 (18\% per year). By type of maltreatment, the greatest proportional increases were in notifications for emotional abuse $(30 \%$ per year) and sexual abuse (27\% per year). For substantiated cases, the greatest proportional increase among Aboriginal children was for emotional abuse, which increased from 0.5 to 10.9 cases per 1000 (30\% per year). Substantiated sexual abuse cases remained relatively uncommon, increasing from 0.7 to 1.8 cases per 1000 (15\% per year). The increase in substantiated physical abuse cases was not statistically significant. Neglect cases increased in number, particularly in 2009 and 2010, to be the dominant type of substantiated maltreatment among Aboriginal children (Box 4).

Among non-Aboriginal children, there was also an increase in the notification rate, from 19.7 per 1000 children in 1999 to 41.8 per 1000 in 2010 (10\% per year) (Box 3). Again, the greatest proportional increases in notification rates were for emotional abuse and sexual abuse (both 16\% per year) (Box 3). Neither the increase over 12 years in the rate of substantiated cases from 4.3 to 6.7 per 1000 nor changes in annual rates for the four types of maltreatment were statistically significant. Physical abuse was the dominant type of substantiated maltreatment among non-Aboriginal children (Box 5).

\section{Number of children reported each year}

During the 12-year study period, the number of Aboriginal children per year involved in notifications increased to 5.8 times the 1999 level (from 561 to 3242 in 2010). The ratio of notifications to the number of children involved in notifications showed no significant change between 1999 (1.29) and 2010 (1.31). The number of Aboriginal children in substantiated cases each year increased to 5.5 times the 1999 level (from 204 to 1125 in 2010). Again, there was no significant change in the ratio of substantiated cases to the number of children involved in cases (1.14 in 1999 and 1.15 in 2010).

Among non-Aboriginal children, the number per year involved in notifications increased from 611 in 1999 to
1135 in 2010, and the ratios of notifications per child for these years were 1.20 and 1.33 respectively (IRR, 1.01; 95\% CI, 0.87-1.17 for all years). The number of non-Aboriginal children in substantiated cases increased from 139 in 1999 to 215 in 2010, while the ratio of substantiated cases per child remained little changed, at 1.09 and 1.12 , respectively (IRR, 1.01; 95\% CI, 0.86-1.18).

\section{Source of notifications}

Notifications by source varied through time (Box 6). For Aboriginal children, reports by police increased 11-fold between 1999-2002 and 2007-2010, and increased as a proportion of all notifications from $12.5 \%$ to $27.9 \%$. In contrast, the twofold increase in notifications by community members was less than the general increase and the relative contribution fell from $35.0 \%$ to $15.8 \%$ of all notifications. There were also shifts in the relative contributions of notification source for non-Aboriginal children. In both populations, the larger increases in notifications by professional groups including police, health professionals and school personnel were in contrast to more modest increases in reporting by community members.

In the most recent period (20072010), the leading reporter groups by maltreatment type for Aboriginal children were police for emotional (59.1\%) and physical (26.2\%) abuse and health professionals for sexual abuse $(34.3 \%)$ and neglect $(27.5 \%)$. For non-Aboriginal children, police were again the leading source of notifications for emotional abuse (35.4\%), community members for neglect (25.8\%) and school personnel for sexual abuse $(23.7 \%)$ and physical abuse (28.4\%).

\section{Discussion}

Our study highlights large increases in both notifications and substantiated cases of child maltreatment in the NT over the 12-year period from 1999 to 2010.

These increases commenced around 2002 when national attention became focused on the maltreatment of Aboriginal children, precipitated by the Gordon Inquiry in WA and rein-
3 Trends in annual rate of notifications and substantiated cases of maltreatment,* Northern Territory children, 1999-2010

\begin{tabular}{lcc} 
& \multicolumn{2}{c}{ Annual change in rate } \\
\cline { 2 - 3 } Maltreatment type & $\begin{array}{c}\text { Notifications, IRR } \\
(95 \% \mathrm{CI})\end{array}$ & $\begin{array}{c}\text { Substantiated cases, } \\
\text { IRR }^{\dagger}(95 \% \mathrm{CI})\end{array}$ \\
\hline Aboriginal children & $1.30(1.23-1.38)$ & $1.30(1.18-1.43)$ \\
Emotional abuse & $1.24^{\ddagger}(1.20-1.28)$ & $1.22^{\ddagger}(1.15-1.30)$ \\
Neglect & $1.12(1.07-1.16)$ & $1.06(0.99-1.14)^{5}$ \\
Physical abuse & $1.27(1.20-1.35)$ & $1.15(1.01-1.32)$ \\
Sexual abuse & $1.21(1.19-1.24)$ & $1.18(1.13-1.23)$ \\
Total & & \\
Non-Aboriginal children & $1.16(1.07-1.26)$ & $1.10(0.93-1.29)^{5}$ \\
Emotional abuse & $1.10(1.03-1.16)$ & $1.05(0.90-1.20)^{5}$ \\
Neglect & $1.06(1.01-1.12)$ & $0.99(0.88-1.11)^{5}$ \\
Physical abuse & $1.16(1.07-1.25)$ & $1.07(0.86-1.33)^{5}$ \\
Sexual abuse & $1.10(1.07-1.14)$ & $1.04(0.96-1.12)^{5}$ \\
Total &
\end{tabular}

IRR = incidence rate ratio. $*$ Estimates based on primary type of maltreatment. †IRR indicates average annual change in notification/ substantiation rate. $\ddagger$ Summary figure conceals acceleration in notification/ substantiation rates for neglect, 2008-2010 (see Box 4). \$ Change not significant.

\section{Trends in annual rate of substantiated cases of child maltreatment by primary type of maltreatment, Northern Territory Aboriginal children, 1999-2010}

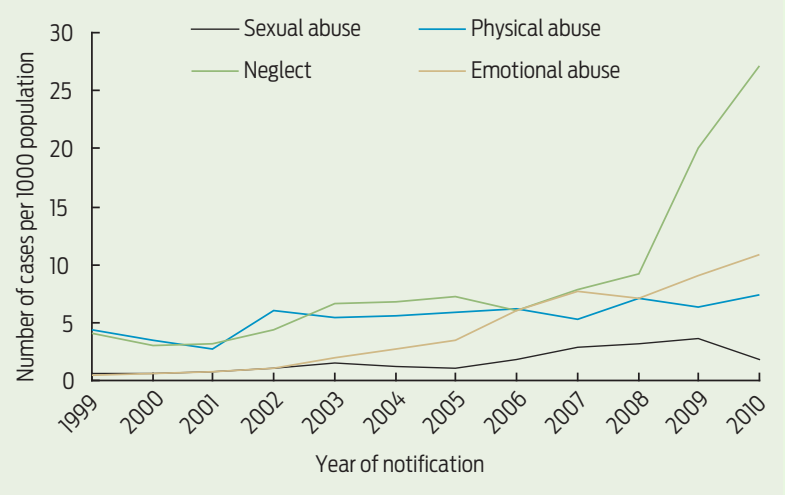

5 Trends in annual rate of substantiated cases of child maltreatment by primary type of maltreatment, Northern Territory non-Aboriginal children, 1999-2010

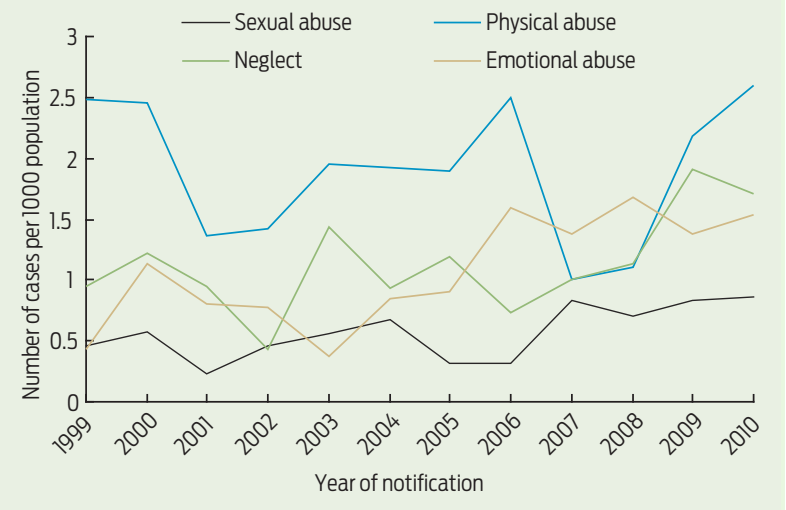


6 Distribution of notifications of suspected child maltreatment, Northern Territory, by reporter group for three time periods: 1999-2002, 2003-2006 and 2007-2010

\begin{tabular}{lcccc} 
& \multicolumn{3}{c}{ Number of notifications* (\%) } \\
\cline { 2 - 4 } & $1999-2002$ & $2003-2006$ & $2007-2010$ & Total \\
\hline Aboriginal children & & & \\
Health professionals & $684(23.4 \%)$ & $1177(20.7 \%)$ & $3392(23.3 \%)$ & $5253(22.7 \%)$ \\
School personnel & $232(8.0 \%)$ & $306(5.4 \%)$ & $1516(10.4 \%)$ & $2054(8.9 \%)$ \\
Police & $365(12.5 \%)$ & $1607(28.2 \%)$ & $4054(27.9 \%)$ & $6026(26.0 \%)$ \\
Social workers and departmental staff & $219(7.5 \%)$ & $370(6.5 \%)$ & $1397(9.6 \%)$ & $1986(8.6 \%)$ \\
Other organisations & $215(7.4 \%)$ & $444(7.8 \%)$ & $914(6.3 \%)$ & $1573(6.8 \%)$ \\
Community members & $1022(35.0 \%)$ & $1489(26.2 \%)$ & $2290(15.8 \%)$ & $4801(20.7 \%)$ \\
Others & $181(6.2 \%)$ & $297(5.2 \%)$ & $976(6.7 \%)$ & $1454(6.3 \%)$ \\
Total & $2918(100 \%)$ & $5690(100 \%)$ & $14539(100 \%)$ & $23147(100 \%)$ \\
Non-Aboriginal children & & & & \\
Health professionals & $150(5.4 \%)$ & $160(4.9 \%)$ & $506(8.5 \%)$ & $816(6.8 \%)$ \\
School personnel & $519(18.5 \%)$ & $539(16.7 \%)$ & $1202(20.3 \%)$ & $2260(18.9 \%)$ \\
Police & $263(9.4 \%)$ & $673(20.8 \%)$ & $1203(20.3 \%)$ & $2139(17.9 \%)$ \\
Social workers and departmental staff & $267(9.5 \%)$ & $302(9.3 \%)$ & $466(7.9 \%)$ & $1035(8.6 \%)$ \\
Other organisations & $193(6.9 \%)$ & $225(7.0 \%)$ & $400(6.7 \%)$ & $818(6.8 \%)$ \\
Community members & $1175(41.9 \%)$ & $1130(34.9 \%)$ & $1532(25.8 \%)$ & $3837(32.1 \%)$ \\
Others & $236(8.4 \%)$ & $207(6.4 \%)$ & $620(10.5 \%)$ & $1063(8.9 \%)$ \\
Total & $2803(100 \%)$ & $3236(100 \%)$ & $5929(100 \%)$ & $11968(100 \%)$ \\
\hline * Record of the primary type of maltreatment was missing for three notifications. & &
\end{tabular}

forced in the following year by Pocock's report of NT services. ${ }^{4,17}$ Pocock reported that, despite mandatory obligations, health providers were reluctant to notify child protection agencies of their concerns, for fear of doing greater harm to children.

Other events also provided early momentum for increased NT notifications, including the Bansemer Report in 2003 that recommended increased attention by government services to statutory and moral child protection obligations. ${ }^{18}$ The recommendation was effected through the Building healthier communities reforms begun in $2004 .{ }^{19}$

The release of the Little children are sacred report ${ }^{8}$ in June 2007 precipitated the Australian Government's Northern Territory National Emergency Response of July 2007. Through this period, there was also legislative reform in the NT that strengthened mandatory reporting obligations in circumstances of both family violence (Domestic and Family Violence Act 2007) and child maltreatment (Care and Protection of Children Act 2007). The new legislation accelerated changes in service response and provided clear guidance for interagency cooperation. The timing of these changes was consistent with the surge in notifications by many of the reporter groups, including health professionals, school personnel and police. The obligations for notification were reinforced during the second NT Inquiry, which during its course called regularly on government services to explain past actions in which children known to services were not protected.

Legislation that underpins mandatory reporting is inconsistent across Australian states and territories, and there are arguments against the rigorous reporting obligations in the NT. ${ }^{20,21}$ One argument is that it leads to increased reports by the public of less serious incidents and, consequently, a reduction in resources for those children most in need of protection. Another is that mandatory reporting leads to more notifications perceptions are challenged by the results in our study. The greatest increase in notifications was not by the public, but by professional groups (police, health workers, school personnel) and this increase led to more investigations and more cases being identified. The reinforcement of mandatory reporting obligations has contributed to the exposure of a previously unrecorded level of need. This is particularly the case for Aboriof the same children. Both of these ginal children, for whom, as described in the Growing them strong, together report, there had been a culture of "normalising the abnormal". ${ }^{13}$ The appropriate response to these changes must not be an attempt to reduce identification, but to provide a sufficient and tailored response to meet the varied needs of vulnerable children. In keeping with the social model outlined in the National framework for protecting Australia's children, ${ }^{22}$ child protection responses in the NT extend to improved housing, income security and health care access. ${ }^{12}$

What is also clear from our results is that there were important differences in the patterns of increase across the types of maltreatment. Among Aboriginal children, the increase in emotional abuse was from a low base and is consistent with new obligations for police to report children exposed to family violence. The pattern of substantiated cases of neglect demonstrates a recent surge, which is consistent with a change in reporting practice for conditions such as malnutrition and for children with inadequate parental supervision. Malnutrition in NT Aboriginal children is not new - "epidemic" levels were documented in the early $1990 \mathrm{~s}^{23}$ - however, it is now being recorded as not only a medical condition but also a child protection concern. For physical abuse, the rate of substantiated cases appears to be stabilising, and the rate for sexual abuse in 2010 was the lowest for several years. Notifications have also increased among the nonAboriginal population, but for all types of maltreatment the ratio of notifications to confirmed cases has been falling, and changes in rates of substantiated cases were not statistically significant.

The analysis of these separate trends in types of maltreatment is important in informing service responses. In the non-Aboriginal population, the stable rate of substantiated cases allows for planning at a more predictable level. By contrast, the rapid increases in both notifications and substantiated cases of maltreatment in the Aboriginal population suggest a need for further expansion of services to address both immediate safety and the wider deter- 
minants of maltreatment, while preventing services from being continually overwhelmed.

Child protection data have well recognised limitations. In particular they are not a measure of child maltreatment incidence. ${ }^{24}$ An analysis is entirely dependent on what is recorded, and as an administrative dataset this will vary between jurisdictions and through time with the policies, practices and resources of the responsible agency. Child maltreatment is loosely defined, and community expectations are changing on what constitutes adequate parenting and the responsibility of government agencies to intervene on a child's behalf. ${ }^{15}$ Nonetheless, child protection data are an emerging source for research in Australia, and one that offers the opportunity for a better understanding of the trends and characteristics of maltreatment. ${ }^{25,26}$ It is information that can assist an understanding of the implications of past policies and services and improve planning for ongoing services for vulnerable children and their families.

Acknowledgements: We thank senior managers in the NT Department of Children and Families and Department of Health for their support for this project, and staff for their diligence over many years of recording and maintaining NT child protection information and for the preparation of the research dataset. Steven Guthridge conducted the project during a period of salaried leave from the NT Government. John Lynch is supported by a National Health and Medical Research Council Australia Fellowship.

Competing interests: No relevant disclosures.

Received 20 Jan 2012, accepted 7 Jun 2012

1 Queensland Crime Commission and Queensland Police Service. Project AXIS. Child sexual abuse in Oueensland: the nature and extent. Vol 1. Brisbane: QCC, 2000. http://www.cmc.qld. gov.au/research-and-publications/browse-allpublications (accessed Oct 2012).

2 Vardon C. The Territory as parent: review of the safety of children in care in the ACT and of ACT child protection management. Canberra: Australian Capital Territory Government, 2004 http://www.dhcs.act.gov.au/_data/assets/pdf file/0014/4901/Review_safety_children_in_ care.pdf (accessed May 2011).

3 Cavanagh $\mathrm{G}$. Inquest into the death of Kalib. Darwin: Coroner's Court, 2010. http://www. nt.gov.au/justice/ntmc/judgements/ 20100119ntmc006.htm (accessed May 2011).

4 Gordon S, Hallahan K, Henry D. Putting the picture together: inquiry into response by government agencies to complaints of family violence and child abuse in Aboriginal communities. Perth: Department of Premier and Cabinet, 2002. http://www.strongfamilies.wa. gov.au/About/How_it_started/Gordon_inquiry (accessed Feb 2011).

5 Mullighan EP; Children in State Care and Children on APY Lands Commission of Inquiry. Children on Anangu Pitjantjatjara Yankunytjatjara (APY) Lands Commission of inquiry. A report into sexual abuse. Adelaide: Parliament of South Australia, 2008. http://www.sa.gov.au/subject/Crime, justice+and+the+law/Mullighan+Inquiry/ Children+on+the+APY+Lands\#Commission (accessed Jan 2012).

6 Aboriginal Child Sexual Assault Taskforce. Breaking the silence: creating the future. Addressing child sexual assault in Aboriginal communities in NSW. Sydney: NSW Attorney General's Department, 2006. http:// www.lawlink.nsw.gov.au/acsat (accessed Feb 2011).

7 Australian Institute of Health and Welfare. Child protection Australia 2009-10. Canberra: AlHW, 2011. (AlHW Cat. No. CWS 39; Child Welfare Series No. 51.) http://www.aihw.gov.au/publicationdetail/?id=6442475448\&tab=2 (accessed Jan 2011).

8 Anderson P, Wild R. Ampe akelyernemane meke mekarle - "little children are sacred". Report of the Northern Territory Board of Inquiry into the Protection of Aboriginal Children from Sexual Abuse. Darwin: Northern Territory Government, 2007. http://www.inquirysaac.nt.gov.au/pdf/ bipacsa_final_report.pdf (accessed Feb 2011).

9 Anderson I. Unexplained differences. Australian Policy Online [internet] 2007; 29 Jun. http://apo. org.au/commentary/unexplained-differences (accessed Jan 2011)

10 Sweet M. Australian efforts to tackle abuse of Aboriginal children raise alarm. BMJ 2007; 335: 691 .

11 Ring IT, Wenitong M. Interventions to halt child abuse in Aboriginal communities. Med J Aust 2007; 187: 204-205

12 Yu P, Duncan ME, Gray B. Northern Territory Emergency Response: Report of the NTER Review Board. Canberra: Australian Government, 2008. http://www.nterreview.gov.au/docs/ report_nter_review/default.htm (accessed Jan 2012).

13 Bamblett M, Bath H, Roseby R. Growing them strong, together: promoting the safety and wellbeing of the Northern Territory's children. Report of the Board of Inquiry into the Child Protection System in the Northern Territory 2010. Darwin: Northern Territory Government, 2010. http://www.childprotectioninquiry.nt.gov.au/ report_of_the_board_of_inquiry (accessed Oct 2011).

14 Holzer P, Bromfield L. Australian legal definitions: when is a child in need of protection? National
Child Protection Clearinghouse resource sheet. Melbourne: Australian Institute of Family Studies, 2010. http://www.aifs.gov.au/nch/pubs/ sheets/rs12/rsl2.html (accessed Jun 2012).

15 Holzer P, Bromfield L. NCPASS comparability of child protection data: project report. Melbourne: Australian Institute of Family Studies, 2008.

16 Australian Bureau of Statistics. Australian demographic statistics, 2007. Canberra: ABS, 2008. (ABS Cat. No. 3101.0.)

17 Pocock J. State of denial: the neglect and abuse of Indigenous children in the Northern Territory. Melbourne: Secretariat, National Aboriginal and Islander Child Care, 2003. http://www.snaicc. asn.au/_uploads/rsfil/01836.pdf (accessed Feb 2011).

18 Banscott Health Consulting. Report of the review of the Northern Territory Department of Health and Community Services (Bansemer report). Darwin: Northern Territory Government, 2003. http://www. health.nt.gov.au/Publications/ Corporate_Publications/index.aspx (accessed Aug 2011).

19 Department of Health and Community Services. Building healthier communities: a framework for health and community services 2004-2009. Darwin: DHCS, 2004. http://hdl.handle.net/ 10137/44 (accessed Nov 2012).

20 Tomison A. Mandatory reporting: a question of theory versus practice. Developing Practice: The Child, Youth and Family Work Journal 2002; 4:13-17.

21 Higgins D, Bromfield L, Richardson N, et al. Mandatory reporting of child abuse and neglect. National Child Protection Clearinghouse resource sheet. Melbourne: NCPC, 2010. http://www.aifs. gov.au/nch/pubs/sheets/rs3/rs3.html (accessed Oct 2011).

22 Council of Australian Governments. Protecting children is everyone's business. National framework for protecting Australia's children 2009-2020. Canberra:Commonwealth of Australia, 2009. http://www.fahcsia.gov.au/ our-responsibilities/families-and-children/ publications-articles/protecting-children-iseveryones-business (accessed Oct 2011).

23 Ruben AR, Walker AC. Malnutrition among rural Aboriginal children in the Top End of the Northern Territory. Med J Aust 1995; 162: 400-403.

24 Sedlak A, Mettenburg J, Basena M, et al. Fourth national incidence study of child abuse and neglect (NIS-4). Report to Congress. Washington, DC: US Department of Health and Human Services, Administration for Children and Families, 2010. https://www.nis4.org/ nishome.asp (accessed Oct 2011).

25 O'Donnell M, Nassar N, Leonard H, et al. Characteristics of non-Aboriginal and Aboriginal children and families with substantiated child maltreatment: a population-based study. Int J Epidemiol 2010; 39: 921-928.

26 Gilbert R, Fluke J, O'Donnell M, et al. Child maltreatment: variation in trends and policies in six developed countries. Lancet 2012; 379: 758-772. 